Georgia State University

ScholarWorks @ Georgia State University

\title{
Specificity of facial expression labeling deficits in childhood psychopathology
}

\author{
Amanda E. Guyer \\ National Institute of Mental Health (NIMH), \\ Erin B. McClure \\ Georgia State University, etone@gsu.edu \\ Abby D. Adler \\ National Institute of Mental Health (NIMH), \\ Melissa A. Brotman \\ National Institute of Mental Health (NIMH), \\ Brendan A. Rich \\ National Institute of Mental Health (NIMH),
}

See next page for additional authors

Follow this and additional works at: https://scholarworks.gsu.edu/psych_facpub

Part of the Psychology Commons

\section{Recommended Citation}

Guyer, Amanda E.; McClure, Erin B.; Adler, Abby D.; Brotman, Melissa A.; Rich, Brendan A.; Kimes, Alane S.; Pine, Daniel S.; Ernst, Monique; and Leibenluft, Ellen, "Specificity of facial expression labeling deficits in childhood psychopathology" (2009). Psychology Faculty Publications. 119.

https://scholarworks.gsu.edu/psych_facpub/119

This Article is brought to you for free and open access by the Department of Psychology at ScholarWorks @ Georgia State University. It has been accepted for inclusion in Psychology Faculty Publications by an authorized administrator of ScholarWorks @ Georgia State University. For more information, please contact scholarworks@gsu.edu. 


\section{Authors}

Amanda E. Guyer, Erin B. McClure, Abby D. Adler, Melissa A. Brotman, Brendan A. Rich, Alane S. Kimes, Daniel S. Pine, Monique Ernst, and Ellen Leibenluft 
Specificity of facial expression labeling deficits in childhood psychopathology

\author{
Amanda E. Guyer, Ph.D. ${ }^{1}$, Erin B. McClure, Ph.D. ${ }^{2}$, Abby D. Adler, B.S. ${ }^{1}$, \\ Melissa A. Brotman, Ph.D. ${ }^{1}$, Brendan A. Rich, Ph.D. ${ }^{1}$, Alane S. Kimes, Ph.D. ${ }^{3}$, \\ Daniel S. Pine, M.D. ${ }^{1}$, Monique Ernst, M.D., Ph.D. ${ }^{1}$, Ellen Leibenluft, M.D. ${ }^{1}$
}

${ }^{1}$ Mood and Anxiety Program (MAP), National Institute of Mental Health (NIMH), National Institutes of Health (NIH), Department of Health and Human Services (DHHS), Bethesda, MD;

${ }^{2}$ Psychology Department, Georgia State University, Atlanta, GA; ${ }^{3}$ Neuroimaging Branch, National Institute of Drug Abuse (NIDA), NIH, DHHS, Baltimore, MD

\title{
Corresponding Author:
}

Amanda E. Guyer, Ph.D.

$\mathrm{MAP} / \mathrm{NIMH} / \mathrm{NIH}$

15K North Drive, Room 208

Bethesda, MD 20892-2670

Phone: 301-594-1378

Fax: 301-402-2010

Email: amandaguyer@mail.nih.gov

Word count (text and references): 5,874 


\begin{abstract}
Background: We examined whether face-emotion labeling deficits are illness-specific or an epiphenomenon of generalized impairment in pediatric psychiatric disorders involving mood and behavioral dysregulation.

Method: Two hundred fifty-two youths (7-18 years old) completed child and adult facial expression recognition subtests from the Diagnostic Analysis of Nonverbal Accuracy (DANVA) instrument. Forty-two participants had bipolar disorder (BD), 39 had severe mood dysregulation (SMD; i.e., chronic irritability, hyperarousal without manic episodes), 44 had anxiety and/or major depressive disorders (ANX/MDD), 35 had attention-deficit/hyperactivity and/or conduct disorder (ADHD/CD), and 92 were controls. Dependent measures were number of errors labeling happy, angry, sad, or fearful emotions.

Results: BD patients made more errors than ANX/MDD, ADHD/CD, or controls when labeling all emotional expressions, whether those expressions were on the faces of children or adults. SMD also showed emotion-labeling deficits, in particular as compared to ANX/MDD patients and controls.
\end{abstract}

Conclusions: Face-emotion labeling deficits differentiate BD and SMD patients from those with ANX/MDD or ADHD/CD and controls. The extent to which such deficits cause vs. result from emotional dysregulation requires further study.

Keywords: Emotion recognition, Bipolar disorder, Emotion regulation, Paediatrics Abbreviations: SMD, DANVA 
The study of face-emotion processing in children with psychopathology may elucidate associations between emotion labeling deficits and social impairment (Nowicki \& Mitchell, 1998). Also, the neural mechanisms mediating face-emotion processing are relatively welldefined (Sprengelmeyer, Rausch, Eysel, \& Przuntek, 1998); thus, identification of emotion labeling deficits in children with psychopathology may implicate specific neural circuits in the pathophysiology of their illness.

Most research on facial affect labeling and psychopathology has focused on adults (Gur et al., 1992; Lembke \& Ketter, 2002; Philippot \& Douilliez, 2005). However, because youth with psychopathology often have social impairment (Geller et al., 2000; Ginsburg, La Greca, \& Silverman, 1998; Maedgen \& Carlson, 2000; Rudolph, Hammen, \& Burge, 1994), studies have begun to examine face-emotion processing in such youth. Much work on face processing in youth has focused on pervasive developmental disorders (PDD), since deficits in social cognition and communication are cardinal features of these conditions (Dawson, Webb, Wijsman et al., 2005). However, significant social impairment is also present in youth with disorders characterized by emotional and/or behavioral dysregulation, including anxiety (ANX), major depression (MDD), attention deficit/hyperactivity (ADHD), conduct disorder (CD), and bipolar disorder (BD). Given that information-processing biases differ across these diagnostic groups (Dalgleish et al., 2003), these disorders may also be characterized by different face-emotion processing profiles.

Indeed, existing studies provide suggestive evidence about differences in emotionprocessing across pediatric diagnostic groups. Some studies link pediatric anxiety and impaired emotion recognition (Easter et al., 2005; Melfsen \& Florin, 2002; Simonian, Beidel, Turner, Berkes, \& Long, 2001); others do not (Manassis \& Young, 2000; McClure, Pope, Hoberman, 
Pine, \& Leibenluft, 2003). One study found that youth with MDD/dysthymia had difficulty recognizing negative emotions (Lenti, Giacobbe, \& Pegna, 2000). Data indicate BD youths have facial expression labeling deficits (McClure et al., 2003; McClure et al., 2005; Rich et al., 2006), consistent with their social problems (Geller et al., 2000; Lewinsohn, Seeley, \& Klein, 2003; Towbin, Pradella, Gorrindo, Pine, \& Leibenluft, 2005). Similarly, ADHD youths have social dysfunction (Maedgen \& Carlson, 2000); while three studies identified emotion recognition deficits in ADHD youth (Corbett \& Glidden, 2000; Pelc, Kornreich, Foisy, \& Dan, 2006; Shapiro, Hughes, August, \& Bloomquist, 1993), another suggested that these deficits reflect inattention rather than misinterpretation of emotions (Cadesky, Mota, \& Schachar, 2000). Together, these studies suggest BD youths have face-emotion labeling deficits, ADHD youths may have deficits linked to inattention or inaccurate encoding, and the performance of anxious and depressed youths is unclear.

The use of different emotion recognition paradigms, however, makes it difficult to compare outcomes across studies. Additionally, most studies compare healthy youth to one, or at most two, psychiatrically-ill groups. Thus, it is unclear whether face-emotion labeling deficits in pediatric psychiatric disorders are illness-specific or epiphenomena of generalized impairment. Specific behavioral deficits may implicate illness-specific neural deficits, facilitating research on the pathophysiology of psychiatric disorders.

We examined face-emotion processing across a range of pediatric psychiatric conditions using a widely-used, standardized emotion recognition paradigm (Cadesky et al., 2000; Manassis \& Young, 2000; Nowicki \& Duke, 1994; Plesa-Skwerer, Faja, Schofield, Verbalis, \& TagerFlusberg, 2006). We compared face-emotion labeling among four patient groups: youth with ANX and/or MDD (ANX/MDD), ADHD and/or CD (ADHD/CD), BD, and patients classified as 
having severe mood dysregulation (SMD) (Leibenluft, Charney, Towbin, Bhangoo, \& Pine, 2003). Children with SMD have severe, chronic irritability and hyperarousal. The SMD syndrome was defined to capture children whose nosologic status vis-a-vis BD is unclear; specifically, it is unknown whether SMD is a pre-pubertal presentation of BD (Leibenluft et al., 2003; Nottelmann et al., 2001) and/or an early manifestation of depression (Brotman et al., 2006; Leibenluft, Cohen, Gorrindo, Brook, \& Pine, 2006). The SMD population is important to study because the syndrome is common (Brotman et al., 2006), impairing, and associated with social dysfunction (Towbin et al., 2005).

Based on data indicating that pediatric BD patients mislabel facial emotion (McClure et al., 2003; McClure et al., 2005; Rich et al., 2006), we hypothesized that they would perform more poorly on face-emotion labeling than all other groups, except for SMD patients. Because SMD shares some clinical features with pediatric $\mathrm{BD}$, and thus may be a phenotype of pediatric BD (Leibenluft et al., 2003), we hypothesized that face-emotion labeling deficits in SMD would be similar to those in BD and differ from those in other patients and controls. Finally, we also examined whether the age of stimulus face or emotion expressed in the face moderated group differences in errors.

\section{Method}

\section{Participants}

The National Institute of Mental Health (NIMH) and National Institute of Drug Abuse (NIDA) Institutional Review Boards approved the study and all participants/parents provided written informed assent/consent. Participants were 7-18 years old. BD $(n=42)$, SMD $(n=39)$, and ANX/MDD ( $n=44)$ patients were enrolled in studies at the NIMH. DSM-IV-based diagnoses were generated from the Schedule for Affective Disorders and Schizophrenia for School-Age 
Children-Present and Lifetime version (K-SADS-PL) (Kaufman et al., 1997). The K-SADS-PL was conducted with children and their parents separately by psychiatrists/psychologists with high inter-rater reliability (kappa $\geq 0.75$, based on blind review of taped evaluations). A K-SADS-PL module determined SMD diagnosis.

BD patients met criteria for the "narrow phenotype" of pediatric BD, including history of at least one (hypo)manic episode meeting DSM-IV-TR duration criteria (i.e., $\geq 4$ days for hypomania, $\geq 7$ days for mania), elevated/expansive mood, and $\geq 3$ other "B" symptoms (Geller et al., 2002; Leibenluft et al., 2003). SMD patients had abnormal baseline mood (anger or sadness, at least half the day most days and noticeable by others), hyper-reactivity to negative emotional stimuli (e.g., explosive, developmentally inappropriate outbursts at least 3x/week), and hyperarousal ( $\geq 3$ of: insomnia, intrusiveness, pressured speech, flight of ideas/racing thoughts, distractibility, psychomotor agitation) (Leibenluft et al., 2003). SMD symptoms must begin before age 12 , occur for $\geq 1$ year without remission exceeding two months, and cause severe impairment (e.g., hospitalization, repeated grade) in $\geq 1$ setting (e.g., home, school, peers) and mild impairment (e.g., poor academic performance, disciplinary problems) in another. Those with euphoric mood or distinct (hypo)manic episodes lasting $\geq 1$ day were excluded from the SMD group.

ANX patients had current generalized anxiety, social phobia, and/or separation anxiety. MDD patients met criteria for current major depression. Other inclusion criteria for ANX/MDD patients were 1) Pediatric Anxiety Rating Scale (PARS) (RUPP, (2002)) scores $\geq 10$ and/or Children's Depression Rating Scale (CDRS) (Poznanski et al., 1984) scores $\geq 39 ; 2$ ) Children’s Global Assessment Scale (CGAS) (Shaffer et al., 1983) scores <60; and 3) persistent anxiety and/or depression (consistently elevated PARS and/or CDRS) during supportive psychotherapy 
(McClure et al., in press; Monk et al., 2006; RUPP, 2001). Among ANX/MDD patients, 26 had ANX, 14 had ANX+MDD, and four had MDD (see Data Analysis for rationale to combine patients).

ADHD/CD participants $(n=35)$ were enrolled in a longitudinal study of risk factors for substance abuse at the NIDA (Ernst et al., 2006). Participants and their parents were administered the Diagnostic Interview for Children and Adolescents (DICA-R), a structured psychiatric interview (Reich, 2000), by trained master's- and bachelor's-level research assistants. Two child psychiatrists used the DICA-R and additional information obtained from adolescents, parents, and teachers to determine DSM-IV-based diagnoses. ADHD/CD patients included 18 with ADHD, 10 with ADHD+CD, and 7 with CD (see Data Analysis).

Controls were 92 adolescents identified as psychiatrically healthy based on the K-SADSPL/DICA-R. Data comparing BD patients $(n=39)$ to subsets of control $(n=24)$ and ANX/MDD $(n=10)$ participants on face-emotion labeling have been published (McClure et al., 2003; McClure et al., 2005).

Exclusion criteria for all groups included: IQ $<70$; unstable/chronic medical illness; history of PDD, head trauma, or substance use within past two months (any substance use history for ADHD/CD). Because the K-SADS and DICA-R do not assess for the presence of PDD, exclusion for PDD was based on history of a PDD diagnosis or clinical observation of severely impaired interpersonal functioning during the diagnostic interview; judgment from experienced clinicians reliably differentiates children with and without PDD (Lord et al., 2006; Mahoney et al., 1998). Children with ANX or MDD were excluded from the ADHD/CD group. Additional exclusion criteria for ANX/MDD and ADHD/CD patients included: current Tourette's syndrome or obsessive compulsive disorder; posttraumatic stress disorder; exposure to extreme trauma; 
Face-emotion labeling deficits

suicidal ideation; history of mania or psychosis; use of psychotropic medications (except stimulants for $\mathrm{ADHD} / \mathrm{CD})$.

Measures

The Diagnostic Analysis of Nonverbal Accuracy (DANVA) (Nowicki \& Duke, 1994) Child and Adult Facial Expressions subtests were used to assess face-emotion labeling. Each computer-administered subtest includes 24 photographs of child or adult models (12 female, 12 male per subtest) displaying equal numbers of high- and low-intensity expressions of happiness, sadness, anger, and fear. Faces appear for 2 seconds. In a forced-choice format, participants indicate by button-press which emotion a face expresses. Both subtests have been standardized and have acceptable internal consistency and reliability (Nowicki \& Carton, 1993; Nowicki \& Duke, 1989; Nowicki \& Duke, 1994). The dependent variable was total errors, i.e., misidentified emotions, created separately for each subtest and each emotion. High- and low-intensity expressions were combined to increase power.

IQ was assessed with the Wechsler Abbreviated Scale of Intelligence (WASI) (Wechsler, 1999) for all but ADHD/CD participants, who completed the abbreviated Wechsler Intelligence Scale for Children (WISC-III) (Wechsler, 1991).

Functional impairment of BD, SMD, and ANX/MDD patients was measured with the CGAS. BD and SMD mood state was assessed at testing using the Young Mania Rating Scale (YMRS) (Young, Biggs, Ziegler, \& Meyer, 1978) and CDRS. However, since, by definition, SMD children have not had a DSM-IV hypomanic or manic episode, elevated YMRS scores in this population indicate hyperarousal, not mania per se. CDRS and YMRS ratings were used to assign mood states as follows: euthymic: YMRS $\leq 12$, CDRS $<40$; depressed: YMRS $<12$, CDRS $>40$; (hypo)manic [BD only]: YMRS >12, CDRS <40; mixed [BD only]: YMRS >12, CDRS 
>40. The Screen for Child Anxiety Related Disorders (SCARED) (Birmaher et al., 1997) assessed severity of anxiety symptoms (scores $\geq 25$ indicate disorder) in ANX/MDD patients. Conners' Parent Rating Scale (Conners, 1989) assessed severity of hyperactivity in ADHD/CD patients at testing.

Data Analysis

ANX, MDD, and ANX+MDD participants, on the one hand, and ADHD, CD, and $\mathrm{ADHD}+\mathrm{CD}$ participants, on the other, were combined to maximize statistical power for two reasons. First, since comorbidity rates among these disorder clusters are high (Axelson \& Birmaher, 2001; Biederman, Newcorn, \& Sprich, 1991), it is not feasible to compare individual disorders. Second, preliminary analyses comparing errors among the narrowly-defined groups indicated similar mean scores among the ANX, MDD, and ANX+MDD groups ( $p$-values: 0.350.93), and among ADHD, CD, and ADHD+CD ( $p$-values: 0.23-0.95). This overlap in performance is supported by other research on face-emotion labeling comparing ANX and ANX+MDD (Monk et al., 2006), and ADHD and CD (Cadesky et al., 2000).

Analyses of variance assessed group differences in age, IQ, and CGAS scores. Significant differences were interpreted with Tukey's pairwise tests. Chi-squares assessed group differences in sex and ethnicity (white or non-white, given small cell sizes for non-white ethnicities). Because of age, IQ, sex, and ethnicity group differences (see Results), these variables served as covariates.

A 5 (group) x 2 (face-age) x 4 (emotion) repeated measures analysis of covariance (ANCOVA) of errors tested main effects of group, face-age, and emotion, and group by face-age and group by emotion interactions. Wilks' Lambda was used to test the significance of withingroup factors and interactions. Significant $F$ statistics were interpreted with Bonferroni-corrected 
post-hoc tests. Analyses used two-tailed significance tests $(\alpha=0.05)$. Partial eta-squared $\left(\eta_{\mathrm{p}}{ }^{2}\right)$ is reported for effect size.

\section{Results}

Demographic and Clinical Characteristics (Tables 1 and 2)

Groups differed in age, $F(4,247)=12.63, p<0.001$; controls and ADHD/CD were older than ANX/MDD, SMD, and BD patients ( $p$-values $<0.02)$. IQ differed among groups, $F(4,247)=2.36, p=0.05$. Controls had higher IQ scores than ADHD/CD patients (mean difference $=8.01, p=0.06$ ); all other groups had comparable IQs. Sex distribution across groups tended to be different, $\chi^{2}(4, N=252)=8.53, p=0.07$; more males were in the ADHD/CD $(71 \%)$ and SMD (72\%) groups than in the other groups. The proportion of white vs. non-white participants was greater among BD and SMD than other groups, $\chi^{2}(4, N=252)=23.87, p<0.001$. Thus, age, IQ, sex, and ethnicity were covariates in all statistical models.

Regarding mood state at testing, $59.5 \%$ of BD $(n=25)$ and $47.6 \%$ of SMD $(n=20)$ patients were euthymic. Of 14 non-euthymic BD patients, 11 were hypomanic and three were in a mixed mood state. Four SMD patients were depressed. Among ANX/MDD patients, $56.8 \%(n=25)$ had elevated anxiety based on the SCARED $(M=27.80 \pm 13.53)$. Among ADHD/CD patients, mean Conners' hyperactivity score was $17.14 \pm 4.16$.

BD, SMD, and ANX/MDD patients' CGAS scores indicated moderate impairment and did not differ significantly (BD: $M=50.27 \pm 11.28$; SMD: $M=48.84 \pm 7.67$; ANX/MDD: $M=49.05 \pm 7.76)$.

Thirty-three BD, $17 \mathrm{SMD}$, and 17 ADHD/CD patients were receiving psychotropic medication. ANX/MDD patients were medication-free.

Emotion Labeling Errors 
A significant main effect indicated that the groups differed in face-emotion labeling errors, $F(4,243)=8.51, p<0.001, \eta_{\mathrm{p}}{ }^{2}=0.12$ (Figure 1). Post-hoc comparisons indicated that BD youth made more errors than all other groups (each $p$-value $<0.001$ ) except SMD. SMD youth committed significantly more errors than ANX/MDD youth $(p=0.03)$. Comparison of SMDs and controls was not significant after Bonferroni-correction; however, because we had an a priori hypothesis concerning this contrast, Bonferroni-correction is conservative. When compared to controls only, SMDs made significantly more errors, $F(1,125)=6.84, p=.01, \eta_{\mathrm{p}}{ }^{2}=0.05$.

A significant emotion effect was also found, $F(3,241)=3.46, p=0.02, \eta_{\mathrm{p}}{ }^{2}=0.04$. Post-hoc tests showed that all subjects made more errors on angry than fearful, sad, and happy expressions; on fearful than sad and happy expressions; and on sad than happy expressions. Interactions between group and face-age or emotion were not significant, indicating that the impact of face-age or emotion on errors did not differ across groups. Increasing age and higher IQ were associated with fewer errors, Age: $F(1,243)=12.25, p=0.001, \eta_{\mathrm{p}}{ }^{2}=0.05$, and IQ: $F(1,243)=13.87, p<0.001, \eta_{\mathrm{p}}^{2}=0.05$.

Post-hoc Analyses

Post-hoc analyses assessed effects of mood state and medications on face-emotion labeling in BD and SMD patients. Euthymic BDs $(n=25)$ and controls $(n=92)$ were compared to examine whether labeling deficits in BDs are trait-related. Euthymic BDs made more errors than controls, $F(1,111)=19.80, p<0.001$. Additionally, euthymic BDs $(n=25)$ and symptomatic BDs $(n=14)$ did not differ in performance, $F(1,33)=0.65, p=0.43$. SMDs were not divided by mood state because an insufficient number were depressed.

Unmedicated BDs $(n=9)$ and unmedicated SMDs $(n=22)$ were each compared to controls and to medicated patients. Unmedicated BDs made more errors $(M=1.80 \pm 0.17)$ than controls 
$(M=0.83 \pm 0.05), F(1,95)=30.65, p<0.001$, and unmedicated BDs $(M=1.84 \pm 0.18)$ made slightly more errors than medicated BDs $(M=1.22 \pm 0.09), F(1,36)=9.23, p=0.004$. Errors were significantly more common in unmedicated SMDs $(M=1.18 \pm 0.10)$ than in controls $(M=0.85 \pm 0.05), F(1,108)=8.36, p=0.005$, but unmedicated and medicated SMDs did not differ in errors, $F(1,33)=0.95, p=0.34$.

\section{Discussion and Conclusion}

We tested the specificity of facial expression labeling deficits in a large sample of youths with disorders characterized by emotional and/or behavioral dysregulation. Two main findings emerged. First, as hypothesized, when labeling emotional expressions in faces, BD patients made more errors than did youths with anxiety and/or MDD, ADHD and/or CD, or controls. Second, SMDs showed face-emotion labeling deficits when judging faces, particularly as compared to ANX/MDD patients and controls.

Past work shows that youths with "narrow phenotype" BD have a deficit in facial affect labeling (McClure et al., 2003; McClure et al., 2005; Rich et al., 2006). The present study extends prior work by demonstrating that this deficit emerges relative to youths with other psychiatric disorders and similar levels of impairment. Additionally, anxiety, ADHD, and CD are common comorbidities in BD patients (Biederman, Faraone, Chu, \& Wozniak, 1999; Carlson, 1998; Dickstein et al., 2005); the current data, indicating that ANX/MDD and ADHD/CD resemble controls on face-emotion labeling ability, suggest that labeling deficits in pediatric BD are probably associated with BD itself, rather than the associated comorbidities.

SMDs were the only group other than BDs to exhibit face-emotion labeling deficits, although SMD deficits were not as marked as BD deficits. In analyses involving all groups, SMDs made more errors than ANX/MDD patients. When compared directly to controls only, 
Face-emotion labeling deficits

SMDs performed significantly worse, providing further support for face-emotion labeling deficits in SMD. Researchers debate whether SMD is a developmental presentation of BD, since emotional lability, irritability, and hyperarousal are prominent in both syndromes (Leibenluft et al., 2003). By measuring face-emotion labeling, our results add a new dimension to the heretofore clinically-focused debate about the classification of these two pediatric BD phenotypes. Our data suggest that the pathophysiology of SMD and BD may overlap, in that both are associated with face-emotion labeling deficits absent in other psychiatrically-ill groups.

$\mathrm{ADHD} / \mathrm{CD}$ and $\mathrm{ANX} / \mathrm{MDD}$ patients performed similarly to controls on face-emotion labeling. Our results replicate those of related studies in ADHD. For example, data indicate that children with ADHD and CD are as accurate as controls on the DANVA (Cadesky et al., 2000), and that ADHD children age 8 and older process facial affective cues as well as controls (Shapiro et al., 1993). In contrast, two studies found 7-12 year olds with ADHD less accurate at labeling emotions than controls (Corbett \& Glidden, 2000; Pelc et al., 2006). In our study, none of the ADHD/CD patients was younger than 12 years. Thus, preadolescent ADHD children could have greater difficulty labeling facial emotions than do older ADHD children.

Data regarding face-emotion labeling in ANX/MDD are inconsistent. Three studies show that children with anxiety misidentify adult emotions (Easter et al., 2005; Melfsen \& Florin, 2002; Simonian et al., 2001), and one study found a similar pattern in depressed children (Lenti et al., 2000). However, two studies using the DANVA (one of which included 10 ANX patients from the current sample) found no differences between anxious and control youths (Manassis \& Young, 2000; McClure et al., 2003). Notably, the present study includes the largest ANX/MDD sample yet reported. As such, these findings suggest the absence of strong associations between ANX/MDD and face-emotion labeling deficits. However, the DANVA assesses face-emotion 
labeling, whereas other studies of anxious youth use tasks designed to assess attentional biases while viewing facial expressions (e.g., dot probe tasks) (Bradley, Mogg, White, Groom, \& de Bono, 1999; Mogg, Philippot, \& Bradley, 2004). Different face-emotion processing tasks may yield different results across patient populations. Finally, different results across studies of faceemotion labeling in anxiety may reflect the fact that our study included youth with a range of anxiety disorders (57\% had social phobia, $46 \%$ had generalized anxiety, $23 \%$ had separation anxiety, and $18 \%$ had specific/simple phobia), whereas other studies only included youth with a specific anxiety disorder such as social phobia (Melfsen \& Florin, 2002; Simonian et al., 2001).

In the current study, in all of the groups, face labeling ability did not differ based on the age of the face or the specific emotion displayed. Thus, BD and SMD patients have deficits labeling emotions on both adult and child faces and across emotions. In an initial study, we found that BD patients made more errors on child than adult faces (McClure et al., 2003). However, in a later study (McClure et al., 2005) and here, we included a much larger sample of $\mathrm{BD}, \mathrm{ANX}$, and control subjects, and found that BD subjects performed poorly when labeling emotions on children's and adults' faces. Across all groups, we found that emotion-specific errors increased in the following order: happiness, sadness, fear, and anger. This is consistent with work documenting greater accuracy for happiness than for negative emotions (Gross \& Ballif, 1991; Mufson \& Nowicki, 1991).

We excluded children with PDD. Like BD and SMD youths, children with PDD have impaired social behavior, including difficulty responding to others' emotional cues (Dawson, Webb, \& McPartland, 2005). Indeed, both BD and SMD youths frequently display some PDD symptoms (Towbin et al., 2005; Wozniak et al., 1997). Thus, further research is needed to understand relationships among BD, SMD, PDD, and face-emotion processing. 
Identification of emotion labeling deficits can guide research on the pathophysiology of SMD and BD. Indeed, research indicates an association between face-emotion labeling deficits and amygdala hyperactivity in youth with BD youth (Rich et al., 2006). Comparative functional magnetic resonance imaging (fMRI) studies of BD and SMD patients will help elucidate whether similar brain/behavior relationships mediate face-emotion processing deficits in these patient groups.

This study should be considered in light of five limitations. First, many BD and SMD patients were taking psychotropic medications at testing. Because medication discontinuation is ethically constrained, it is difficult to recruit pediatric patients who are severely impaired but unmedicated. However, post-hoc analyses demonstrated that even unmedicated BD and SMD patients performed significantly worse than controls. Unmedicated and medicated SMD patients did not perform differently; although the performance of unmedicated and medicated BD patients differed, both groups performed significantly worse than controls. Indeed, even within smaller samples of unmedicated SMD or BD youths, labeling deficits were evident.

Second, comorbidity was high in $\mathrm{BD}$, although comparable to rates reported in other pediatric BD studies (Biederman et al., 1999). For example, $69 \%$ of BD patients had anxiety and 59\% had ADHD diagnoses. However, as noted above, given that subjects with ANX/MDD or $\mathrm{ADHD} / \mathrm{CD}$ were unimpaired on face-emotion labeling, it is unlikely that the presence of these conditions in children with BD accounts for their deficits. Third, BDs were tested irrespective of current mood state. However, emotion labeling deficits were present in euthymic BDs, suggesting that face-emotion misidentification may be a trait-based deficit in BD.

Fourth, group differences in demographic characteristics (e.g., age, IQ, sex, ethnicity) may bias our results, although our analyses covaried these variables. We did not find that 
emotion labeling ability varied by sex, but subsequent studies should include more females and a broader range of ages and ethnicities, particularly in $\mathrm{ADHD} / \mathrm{CD}, \mathrm{BD}$, and SMD samples.

Finally, although the DANVA is a standardized emotion labeling paradigm, the number of test items is small ( 24 child and 24 adult faces), particularly when broken down by emotions (6 faces per emotion per face-age). Therefore, the power to detect emotion-specific differences is limited.

This study has two key clinical implications. First, combining pathophysiologically- and clinically-based measures can help address nosological questions. The identification of behavioral deficits common to both the narrow-BD and broad-SMD phenotypes informs discussion about the nosological relationship between these two syndromes (Leibenluft et al., 2003). Additionally, the face-emotion labeling deficits reported here may indicate dysfunctional neural circuitry. As such, documented behavioral/cognitive impairments can be targeted for study with fMRI to identify neural correlates of underlying behavioral deficits, elucidate pathophysiology, and inform nosology. Second, documenting behavioral deficits specific to certain psychiatric disorders can aid in identifying targets for intervention. For example, an intervention developed for children with PDD has used rewards to reinforce facial stimuli and increase motivation for social interactions (Dawson \& Zanolli, 2003). Our results suggest that social skills training with a facial affect labeling component may be an important part of treatment for BD and SMD youths.

Acknowledgments: This work was supported by the NIMH and NIDA Intramural Research Programs. 


\section{References}

Axelson, D. A., \& Birmaher, B. (2001). Relation between anxiety and depressive disorders in childhood and adolescence. Depress Anxiety, 14(2), 67-78.

Biederman, J., Faraone, S. V., Chu, M. P., \& Wozniak, J. (1999). Further evidence of a bidirectional overlap between juvenile mania and conduct disorder in children. $J \mathrm{Am}$ Acad Child Adolesc Psychiatry, 38(4), 468-476.

Biederman, J., Newcorn, J., \& Sprich, S. (1991). Comorbidity of attention deficit hyperactivity disorder with conduct, depressive, anxiety, and other disorders. Am J Psychiatry, 148(5), 564-577.

Birmaher, B., Khetarpal, S., Brent, D., Cully, M., Balach, L., Kaufman, J., et al. (1997). The Screen for Child Anxiety Related Emotional Disorders (SCARED): scale construction and psychometric characteristics. J Am Acad Child Adolesc Psychiatry, 36(4), 545-553.

Bradley, B. P., Mogg, K., White, J., Groom, C., \& de Bono, J. (1999). Attentional bias for emotional faces in generalized anxiety disorder. Br J Clin Psychol, 38 ( Pt 3), 267-278.

Brotman, M. A., Schmajuk, M., Rich, B. A., Dickstein, D. P., Guyer, A. E., Costello, E. J., et al. (2006). Prevalence, clinical correlates, and longitudinal course of severe mood dysregulation in children. Biol Psychiatry, 60(9), 991-997.

Cadesky, E. B., Mota, V. L., \& Schachar, R. J. (2000). Beyond words: how do children with ADHD and/or conduct problems process nonverbal information about affect? J Am Acad Child Adolesc Psychiatry, 39(9), 1160-1167.

Carlson, G. A. (1998). Mania and ADHD: comorbidity or confusion. J Affect Disord, 51(2), $177-$ 187. 
Conners, C. (1989). Manual for Conners' Rating Scales. North Tonawanda, NY: Multi-Health Systems, Inc.

Corbett, B., \& Glidden, H. (2000). Processing affective stimuli in children with attention-deficit hyperactivity disorder. Child Neuropsychol, 6(2), 144-155.

Dalgleish, T., Taghavi, R., Neshat-Doost, H., Moradi, A., Canterbury, R., \& Yule, W. (2003). Patterns of processing bias for emotional information across clinical disorders: a comparison of attention, memory, and prospective cognition in children and adolescents with depression, generalized anxiety, and posttraumatic stress disorder. J Clin Child Adolesc Psychol, 32(1), 10-21.

Dawson, G., Webb, S. J., \& McPartland, J. (2005). Understanding the nature of face processing impairment in autism: insights from behavioral and electrophysiological studies. Dev Neuropsychol, 27(3), 403-424.

Dawson, G., Webb, S. J., Wijsman, E., Schellenberg, G., Estes, A., Munson, J., et al. (2005). Neurocognitive and electrophysiological evidence of altered face processing in parents of children with autism: implications for a model of abnormal development of social brain circuitry in autism. Dev Psychopathol, 17(3), 679-697.

Dawson, G., \& Zanolli, K. (2003). Early intervention and brain plasticity in autism. In M. Rutter (Ed.), Autism: Neural bases and treatment possibilities (pp. 266-280). London: Novartis.

Dickstein, D. P., Rich, B. A., Binstock, A. B., Pradella, A. G., Towbin, K. E., Pine, D. S., et al. (2005). Comorbid anxiety in phenotypes of pediatric bipolar disorder. J Child Adolesc Psychopharmacol, 15(4), 534-548. 
Easter, J., McClure, E. B., Monk, C. S., Dhanani, M., Hodgdon, H., Leibenluft, E., et al. (2005). Emotion recognition deficits in pediatric anxiety disorders: implications for amygdala research. J Child Adolesc Psychopharmacol, 15(4), 563-570.

Ernst, M., Luckenbaugh, D. A., Moolchan, E. T., Leff, M. K., Allen, R., Eshel, N., et al. (2006). Behavioral predictors of substance-use initiation in adolescents with and without attention-deficit/hyperactivity disorder. Pediatrics, 117(6), 2030-2039.

Geller, B., Bolhofner, K., Craney, J. L., Williams, M., DelBello, M. P., \& Gundersen, K. (2000). Psychosocial functioning in a prepubertal and early adolescent bipolar disorder phenotype. J Am Acad Child Adolesc Psychiatry, 39(12), 1543-1548.

Geller, B., Zimerman, B., Williams, M., Delbello, M. P., Bolhofner, K., Craney, J. L., et al. (2002). DSM-IV mania symptoms in a prepubertal and early adolescent bipolar disorder phenotype compared to attention-deficit hyperactive and normal controls. J Child Adolesc Psychopharmacol, 12(1), 11-25.

Ginsburg, G. S., La Greca, A. M., \& Silverman, W. K. (1998). Social anxiety in children with anxiety disorders: relation with social and emotional functioning. J Abnorm Child Psychol, 26(3), 175-185.

Gross, A. L., \& Ballif, B. (1991). Children's understanding of emotion from facial expressions and situations: A review Developmental Review 11, 368-398.

Gur, R. C., Erwin, R. J., Gur, R. E., Zwil, A. S., Heimberg, C., \& Kraemer, H. C. (1992). Facial emotion discrimination: II. Behavioral findings in depression. Psychiatry Res, 42(3), 241251.

Kaufman, J., Birmaher, B., Brent, D., Rao, U., Flynn, C., Moreci, P., et al. (1997). Schedule for Affective Disorders and Schizophrenia for School-Age Children-Present and Lifetime 
Version (K-SADS-PL): initial reliability and validity data. J Am Acad Child Adolesc Psychiatry, 36(7), 980-988.

Leibenluft, E., Charney, D. S., Towbin, K. E., Bhangoo, R. K., \& Pine, D. S. (2003). Defining clinical phenotypes of juvenile mania. Am J Psychiatry, 160(3), 430-437.

Leibenluft, E., Cohen, P., Gorrindo, T., Brook, J. S., \& Pine, D. S. (2006). Chronic vs. episodic irritability in youth: A community-based, longitudinal study of clinical and diagnostic associations. J Child Adolesc Psychopharmacol, 16(4), 456-466.

Lembke, A., \& Ketter, T. A. (2002). Impaired recognition of facial emotion in mania. Am J Psychiatry, 159(2), 302-304.

Lenti, C., Giacobbe, A., \& Pegna, C. (2000). Recognition of emotional facial expressions in depressed children and adolescents. Percept Mot Skills, 91(1), 227-236.

Lewinsohn, P. M., Seeley, J. R., \& Klein, D. N. (2003). Bipolar disorders during adolescence. Acta Psychiatr Scand Suppl(418), 47-50.

Lord, C., Risi, S., DiLavore, P. S., Shulman, C., Thurm, A., \& Pickles, A. (2006). Autism from 2 to 9 years of age. Arch Gen Psychiatry, 63(6), 694-701.

Maedgen, J. W., \& Carlson, C. L. (2000). Social functioning and emotional regulation in the attention deficit hyperactivity disorder subtypes. J Clin Child Psychol, 29(1), 30-42.

Mahoney, W. J., Szatmari, P., MacLean, J. E., Bryson, S. E., Bartolucci, G., Walter, S. D., et al. (1998). Reliability and accuracy of differentiating pervasive developmental disorder subtypes. J Am Acad Child Adolesc Psychiatry, 37(3), 278-285.

Manassis, K., \& Young, A. (2000). Perception of emotions in anxious and learning disabled children. Depress Anxiety, 12(4), 209-216. 
McClure, E. B., Monk, C. S., Nelson, E. E., Parrish, J. M., Adler, A., Blair, R. J., et al. (in press). Abnormal attention modulation of fear circuit function in pediatric generalized anxiety disorder Arch Gen Psychiatry.

McClure, E. B., Pope, K., Hoberman, A. J., Pine, D. S., \& Leibenluft, E. (2003). Facial expression recognition in adolescents with mood and anxiety disorders. Am J Psychiatry, 160(6), 1172-1174.

McClure, E. B., Treland, J. E., Snow, J., Schmajuk, M., Dickstein, D. P., Towbin, K. E., et al. (2005). Deficits in social cognition and response flexibility in pediatric bipolar disorder. Am J Psychiatry, 162(9), 1644-1651.

Melfsen, S., \& Florin, I. (2002). Do socially anxious children show deficits in classifying facial expressions of emotions? Journal of Nonverbal Behavior, 26(2), 109-126.

Mogg, K., Philippot, P., \& Bradley, B. P. (2004). Selective attention to angry faces in clinical social phobia. J Abnorm Psychol, 113(1), 160-165.

Monk, C. S., Nelson, E. E., McClure, E. B., Mogg, K., Bradley, B. P., Leibenluft, E., et al. (2006). Ventrolateral prefrontal cortex activation and attentional bias in response to angry faces in adolescents with generalized anxiety disorder. Am J Psychiatry, 163(6), 10911097.

Mufson, L., \& Nowicki, S., Jr. (1991). Factors affecting the accuracy of facial affect recognition. J Soc Psychol, 131(6), 815-822.

Nottelmann, E., Biederman, J., Birmaher, B., Carlson, G. A., Chang, K. D., Fenton, W. S., et al. (2001). National Institute of Mental Health research roundtable on prepubertal bipolar disorder. Journal of the American Academy of Child \& Adolescent Psychiatry, 40(8), 871-878. 
Nowicki, S., \& Carton, J. (1993). The measurement of emotional intensity from facial expressions. Journal of Social Psychology, 133(5), 749-750.

Nowicki, S., \& Duke, M. (1989). A measure of nonverbal social processing ability in children between the ages of 6 and 10. Paper presented at the American Psychological Society, Alexandria, VA.

Nowicki, S., \& Duke, M. P. (1994). Individual differences in the nonverbal communication of affect: The Diagnostic Analysis of Nonverbal Accuracy Scale. Journal of Nonverbal Behavior, 18(1), 9-35.

Nowicki, S., Jr., \& Mitchell, J. (1998). Accuracy in identifying affect in child and adult faces and voices and social competence in preschool children. Genet Soc Gen Psychol Monogr, 124(1), 39-59.

Pelc, K., Kornreich, C., Foisy, M. L., \& Dan, B. (2006). Recognition of emotional facial expressions in attention-deficit hyperactivity disorder. Pediatr Neurol, 35(2), 93-97.

Philippot, P., \& Douilliez, C. (2005). Social phobics do not misinterpret facial expression of emotion. Behav Res Ther, 43(5), 639-652.

Plesa-Skwerer, D., Faja, S., Schofield, C., Verbalis, A., \& Tager-Flusberg, H. (2006). Perceiving Facial and Vocal Expressions of Emotion in Individuals With Williams Syndrome. American Journal on Mental Retardation Vol, 111(1), 15-26.

Poznanski, E. O., Grossman, J. A., Buchsbaum, Y., Banegas, M., Freeman, L., \& Gibbons, R. (1984). Preliminary studies of the reliability and validity of the children's depression rating scale. J Am Acad Child Psychiatry, 23(2), 191-197.

Reich, W. (2000). Diagnostic interview for children and adolescents (DICA). J Am Acad Child Adolesc Psychiatry, 39(1), 59-66. 
Rich, B. A., Vinton, D. T., Roberson-Nay, R., Hommer, R. E., Berghorst, L. H., McClure, E. B., et al. (2006). Limbic hyperactivation during processing of neutral facial expressions in children with bipolar disorder. Proc Natl Acad Sci U S A, 103(23), 8900-8905.

Rudolph, K. D., Hammen, C., \& Burge, D. (1994). Interpersonal functioning and depressive symptoms in childhood: addressing the issues of specificity and comorbidity. $J$ Abnorm Child Psychol, 22(3), 355-371.

RUPP. (2001). Fluvoxamine for the treatment of anxiety disorders in children and adolescents. . N Engl J Med, 344(17), 1279-1285.

RUPP. (2002). The Pediatric Anxiety Rating Scale (PARS): development and psychometric properties. J Am Acad Child Adolesc Psychiatry, 41(9), 1061-1069.

Shaffer, D., Gould, M. S., Brasic, J., Ambrosini, P., Fisher, P., Bird, H., et al. (1983). A children's global assessment scale (CGAS). Arch Gen Psychiatry, 40(11), 1228-1231.

Shapiro, E. G., Hughes, S. J., August, G. J., \& Bloomquist, M. L. (1993). Processing of emotional information in children with attention-deficit hyperactivity disorder. Developmental Neuropsychology, 9(3-4), 207-224.

Simonian, S. J., Beidel, D. C., Turner, S. M., Berkes, J. L., \& Long, J. H. (2001). Recognition of facial affect by children and adolescents diagnosed with social phobia. Child Psychiatry Hum Dev, 32(2), 137-145.

Sprengelmeyer, R., Rausch, M., Eysel, U. T., \& Przuntek, H. (1998). Neural structures associated with recognition of facial expressions of basic emotions. Proc Biol Sci, 265(1409), 1927-1931. 
Towbin, K. E., Pradella, A., Gorrindo, T., Pine, D. S., \& Leibenluft, E. (2005). Autism spectrum traits in children with mood and anxiety disorders. J Child Adolesc Psychopharmacol, $15(3), 452-464$.

Wechsler, D. (1991). Wechsler Intelligence Scale for Children (3rd ed.). San Antonio, TX: Harcourt and Brace.

Wechsler, D. (1999). Wechsler Abbreviated Scale of Intelligence. San Antonio, TX: The Psychological Corporation.

Wozniak, J., Biederman, J., Faraone, S. V., Frazier, J., Kim, J., Millstein, R., et al. (1997). Mania in children with pervasive developmental disorder revisited. J Am Acad Child Adolesc Psychiatry, 36(11), 1552-1559; discussion 1559-1560.

Young, R. C., Biggs, J. T., Ziegler, V. E., \& Meyer, D. A. (1978). A rating scale for mania: reliability, validity and sensitivity. Br J Psychiatry, 133, 429-435. 
Table 1. Demographic characteristics

\begin{tabular}{lccccccccc}
\hline & $\begin{array}{c}\text { BD } \\
(n=42)\end{array}$ & $\begin{array}{c}\text { SMD } \\
(n=39)\end{array}$ & $\begin{array}{c}\text { ANX/MDD } \\
(n=44)\end{array}$ & $\begin{array}{c}\text { ADHD/CD } \\
(n=35)\end{array}$ & $\begin{array}{c}\text { Controls } \\
(n=92)\end{array}$ & $d f$ & $F$ & $\chi^{2}$ & $p$ \\
\cline { 1 - 2 } Age (Years; Mean \pm SD) & $12.8 \pm 2.5$ & $11.8 \pm 2.1$ & $13.1 \pm 2.5$ & $14.8 \pm 1.6$ & $14.4 \pm 2.4$ & 247 & 12.63 & - & 0.000 \\
IQ (Mean \pm SD) & $108.5 \pm 14.5$ & $104.9 \pm 14.9$ & $109.4 \pm 15.6$ & $100.7 \pm 15.5$ & $108.7 \pm 15.3$ & 247 & 2.36 & - & 0.054 \\
Male, $n(\%)$ & $22(52.4)$ & $28(71.8)$ & $23(52.3)$ & $25(71.4)$ & $47(51.1)$ & 252 & - & 8.53 & 0.074 \\
White ethnicity, $n(\%)$ & $41(97.6)$ & $36(92.3)$ & $30(68.2)$ & $21(60.0)$ & $68(73.9)$ & 252 & - & 23.87 & 0.000 \\
\hline
\end{tabular}

Note: $\mathrm{BD}=$ Bipolar disorder; $\mathrm{SMD}=$ Severe mood dysregulation; $\mathrm{ANX} / \mathrm{MDD}=$ Anxiety and/or Major depressive disorders;

$\mathrm{ADHD} / \mathrm{CD}=$ Attention-deficit/hyperactivity and/or Conduct disorder. Groupings based on current diagnoses. 
Table 2. Clinical characteristics

\begin{tabular}{|c|c|c|c|c|}
\hline & $\begin{array}{c}\mathrm{BD} \\
(n=42)\end{array}$ & $\begin{array}{l}\text { SMD } \\
(n=39)\end{array}$ & $\begin{array}{c}\text { ANX/MDD } \\
(n=44)\end{array}$ & $\begin{array}{c}\mathrm{ADHD} / \mathrm{CD} \\
(n=35)\end{array}$ \\
\hline \multicolumn{5}{|l|}{ Lifetime diagnoses, $n(\%)$} \\
\hline Bipolar I & $33(78.6)$ & - & - & - \\
\hline Bipolar II & $9(21.4)$ & - & - & - \\
\hline Anxiety disorder & $29(69.0)$ & $24(61.5)$ & $40(90.9)$ & - \\
\hline Social phobia & $7(16.7)$ & $6(15.4)$ & $25(56.8)$ & - \\
\hline Generalized anxiety & $17(40.5)$ & $15(38.5)$ & $20(45.5)$ & - \\
\hline Panic disorder & $4(9.5)$ & 0 & 0 & - \\
\hline Separation anxiety & $15(35.7)$ & $14(35.9)$ & $8(18.2)$ & - \\
\hline Specific/simple phobia & $12(28.6)$ & $8(20.5)$ & $10(22.7)$ & - \\
\hline Major depressive disorders ${ }^{a}$ & - & $9(23.1)$ & $18(40.9)$ & - \\
\hline Attention deficit/hyperactivity disorder & $25(59.5)$ & $31(79.5)$ & $4(9.1)$ & $28(80.0)$ \\
\hline Conduct disorder & 0 & $1(2.6)$ & 0 & $17(48.6)$ \\
\hline Oppositional defiant disorder & $18(40.9)$ & $34(82.9)$ & $11(23.9)$ & $1(2.8)$ \\
\hline Psychosis & $8(19.0)$ & 0 & - & - \\
\hline \multicolumn{5}{|l|}{ Current medications, $n(\%)^{\mathrm{b}}$} \\
\hline None & $9(21.4)$ & $22(56.4)$ & $44(100.0)$ & $18(51.4)$ \\
\hline Atypical antipsychotic & 26(61.9) & $9(23.1)$ & - & $1(2.9)$ \\
\hline Lithium & $14(33.3)$ & $8(20.5)$ & - & 0 \\
\hline Antiepileptic & $27(64.3)$ & $8(20.5)$ & - & 0 \\
\hline Stimulant & $10(21.4)$ & $8(20.5)$ & - & $16(45.7)$ \\
\hline Non-stimulant for ADHD & $1(2.4)$ & $2(5.1)$ & - & $4(11.4)$ \\
\hline Antidepressant & $15(35.7)$ & $3(7.7)$ & - & $8(22.9)$ \\
\hline
\end{tabular}

Note: Comorbid diagnosis categories are not mutually exclusive within groups. ${ }^{\mathrm{a}}$ Thirty-one BD

had a history of a major depressive episode in addition to a euphoric manic episode. ${ }^{b}$ Except for ANX/MDD, most patients were taking multiple medications at testing. 


\section{Figure Caption}

Figure 1. Facial expression labeling errors.

Notes: $\mathrm{BD}=$ Bipolar disorder; $\mathrm{SMD}=$ Severe mood dysregulation; $\mathrm{ANX} / \mathrm{MDD}=$ Anxiety and/or Major depressive disorders; $\mathrm{ADHD} / \mathrm{CD}=$ Attention-deficit/hyperactivity and/or Conduct disorder. Group effect: $\mathrm{BD}>\mathrm{ADHD} / \mathrm{CD}, \mathrm{ANX} / \mathrm{MDD}$, and Controls, $p<0.001$; $\mathrm{SMD}>\mathrm{ANX} / \mathrm{MDD}$, $p<0.05$; Emotion effect: Angry $>$ Fearful, Sad, and Happy; Fearful $>$ Sad and Happy; Sad $>$ Happy; all p's $\leq 0.001$. Means adjusted for age, sex, ethnic group, and IQ. 


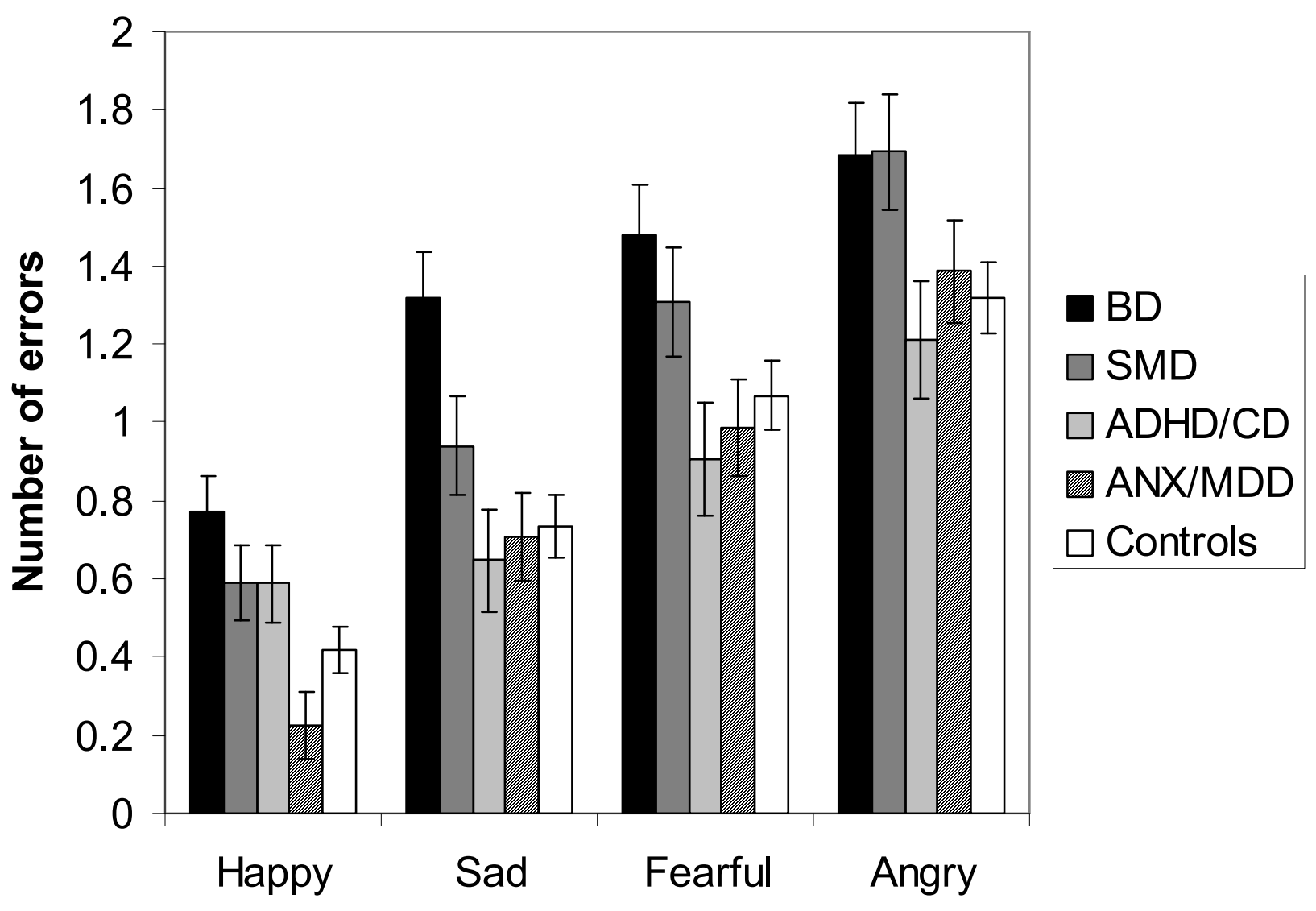

